Alma Mater Studiorum - Università di Bologna DEPARTMENT OF ECONOMICS

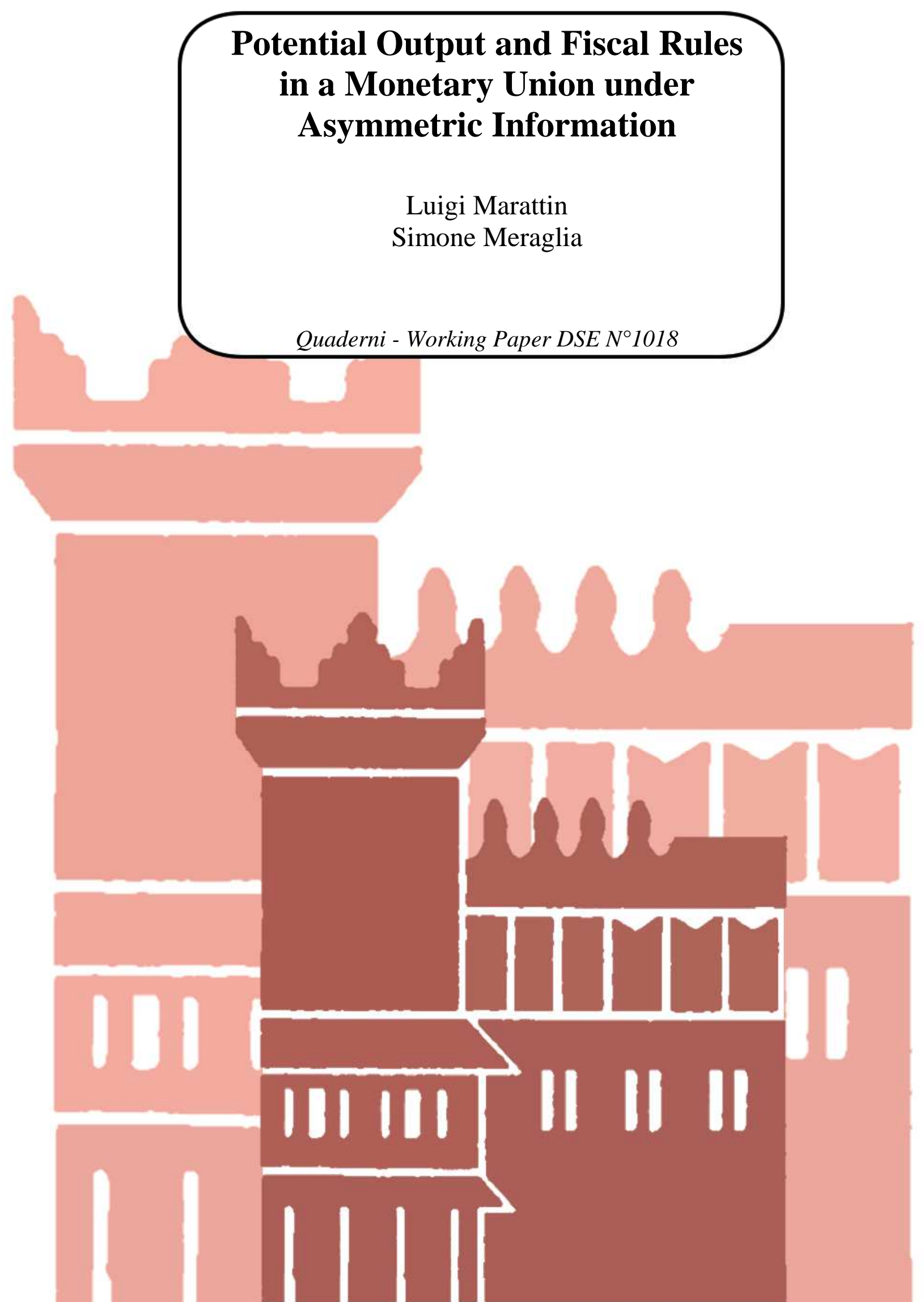




\title{
Potential Output and Fiscal Rules in a Monetary Union under
}

\section{Asymmetric Information*}

\author{
Luigi Marattin†, Simone Meraglia ${ }^{\ddagger}$
}

July 9, 2015

\begin{abstract}
We analyze fiscal rules within a Monetary Union in the presence of (i) asymmetric information about member states' potential output and, therefore, output gap and (ii) bail-out among member states. In our framework, bail-out lowers the scope for signalling (discrimination) by member states (lenders). In the presence of asymmetric information, bail-out and national governments' shortsightedness make the first-best fiscal rule non-implementable as member states are tempted to run excessively high deficits. The Monetary Union designs a mechanism such that member states with high output gap (i.e., in a recession) run higher budget deficits by making an ex-post transfer to the Union. We find that the first-best deficit is contingent on the cycle - i.e., on the member state's output gap - and, all else equal, can be implemented provided the member states' ability to repay its own debt upon the realization of a bad shock is sufficiently high. A downward distortion in the deficit run by a member state during an expansion is otherwise introduced. Finally, the Monetary Union cannot discriminate among types of borrowers when national governments are excessively shortsighted.
\end{abstract}

Keywords: Monetary Union, Output Gap, Asymmetric Information, Bail-Out, Fiscal Rules.

JEL Classification Numbers: E62, D82, F33, F34.

*For helpful comments, we are grateful to Paolo Manasse and Giacomo Calzolari. We also thank seminar participants at the University of Bologna and the ESM (European Stability Mechanism) in Luxembourg, and particpants at the 2015 PET Conference in Luxembourg.

${ }^{\dagger}$ Department of Economics, University of Bologna. Email: luigi.marattin@unibo.it

${ }^{\ddagger}$ Department of Economics, University of Exeter. Email: s.meraglia@exeter.ac.uk 


\section{Introduction}

The debate about fiscal rules within a Monetary Union - and, especially, within the European Monetary Union - has recently attracted much attention from scholars and policymakers alike. Fiscal rules within the European Monetary Union have been anchored to the '3\%-rule' since the Maastricht Treaty. According to this much controversial rule, member states must converge over time towards a deficit/GDP ratio not higher than 3\%. Within this framework, one of the main rationale for imposing a cap on member states' deficit is represented by the possibility - perceived by the financial market - that less 'virtuous' member states might benefit from more 'virtuous' members' financial help (bail-out) and, therefore, fail to internalize the externality they impose on the Union. Since 2013, the 'Fiscal Compact' has modified the set of fiscal constraints in the European Monetary Union and created a new set of rules based on 'cyclically-adjusted' deficit targets. However, the effectiveness of targeting a policy variable whose value is adjusted for business cycle fluctuations relies on the observation of each country's potential output level, which is - at best - very hard to identify and gives rise to many controversies between the European Commission and member states' governments.

In this paper we treat the issue of designing fiscal rules as a standard asymmetric information problem and we propose a mechanism able to deliver the optimal nominal deficit choice by member states. Our main assumptions - for which we provide ample justifications - are that (i) national governments know their potential output better than the Monetary Union decision-making body does, and (ii) the marginal benefit of deficit spending is increasing with the magnitude of the (negative) output gap. We build a model in which (potential) bail-out among member states, on the one hand, makes them less eager to signal their type to the financial market while, on the other hand, it makes them more eager to inefficiently over-borrow on the financial market. Provided national governments are sufficiently longsighted, the Monetary Union can re-establish (possibly constrained) efficiency by designing a mechanism in which a higher cap on deficit is allowed to members experiencing a recession - with respect to the lower cap imposed on those experiencing an expansion - upon payment of a lump-sum transfer to the Union.

Scholars have largely debated on the need for public finance constraints in a Monetary Union with decentralized fiscal policies. Dixit and Lambertini [2001] and Dixit [2001] among others, argue that the need for constraints to fiscal policies arise as an unconstrained fiscal behaviour can affect and undermine monetary committment. ${ }^{1}$ Externalities among member states within a Monetary Union are channeled by at least three related mechanisms: (i) the upward pressure on the common interest rate that would result from an unlimited deterioration of national fiscal aggregates, (ii) the risk of bail-out of the undisciplined member state,

\footnotetext{
${ }^{1}$ For analyses on optimal country-specific fiscal stabilization policies, see Galì and Monacelli [2005] and Ferrero [2009].
} 
and (iii) the risk of financial contagion through a capital market which is further integrated by the absence of exchange rate risk in trading different member states' financial assets. Fiscal rules are then designed to prevent such externalities. The debate on their exact specification has always been lively. Literature debates between deficit-based rules (Artis and Buti [2000], Brunila [2002], Buti et al. [2002], and Wyplosz [2002]) and expenditure-based rules (Bruck and Zwiener [2006]) according to the best stabilization properties. At the same time, the possibility that fiscal rules could be sub-optimal has emerged. If the central bank is sufficiently committed to its future policy (Chari and Kehoe [1998]), if shocks are idiosyncratic (Cooper and Kempf [2000]), or in the presence of intra-EU competitiveness differentials (Engwerda [2002]), then a fiscally-constrained monetary union can be welfare-reducing and lead to suboptimal stabilization of output and prices at the national level.

This paper assumes away the potential benefits deriving from a Monetary Union, and focuses on the potential sub-optimality that can arise from cyclically-adjusted fiscal rules because of the interaction between (i) asymmetric information over the member states' true potential output level and (ii) intra-Union potential bail-out. Bottazzi and Manasse [2005] acknowledge the existence of an important information asymmetry between member states in a Monetary Union regarding domestic macroeconomic conditions. Bordignon et al. [2001] also assume the presence of such an asymmetry between government layers and analyze the optimal income redistribution in a federal state where the true regional tax bases are private information. In line with these contributions, in our model the information asymmetry between the Monetary Union decision-making body and member states' governments concerns the underlying member states' potential output level. For instance, each member state's potential output is a function of the national government's past (structural) investments, where the efficiency of past investments - e.g., the fraction of investments that is not spent in socially wasteful private perks - is the national government's private information.

We show that the problem of asymmetric information is exacerbated by the presence of potentail bailout among member states, because bail-out lessens the standard cross-subsidization between different types (i.e., low versus high potential output) of each single borrower, while at the same time fosters inefficient over-borrowing on the financial market, and especially so by the type that needs it the least. Given the interaction between bail-out and asymmetric information, the Monetary Union can restor (possibly constrained-) efficiency by designing a mechanism requiring member states experiencing a recession and - therefore - more in need of larger budget deficits, to borrow on the financial market by committing to transfer ex-post a lump-sum to the Union. Discriminating between a member state's types requires that different types differ both when good and bad shocks hit their economy though. Hence, a downward distortion in the level of borrowing by member states experiencing an expansion must be introduced when, all else equal, the ability to 
repay the debt is relatively low upon the realization of a bad shock. Finally, excessively shortsighted national governments hinders the mechanism designed by the Monetary Union as they become less concerned with ex-post payments.

The remainder of this paper proceeds as follows. Section 2 illustrates the current set of fiscal rules in the European Monetary Union and discusses costs and benefits of targeting cyclically-adjusted variables. Section 3 lays out the model. We first solve the model under complete information and show how bail-out fosters over-borrowing in the absence of fiscal rules at the Union level. We then solve the model under incomplete information, show the interaction between bail-out and asymmetric information, and describe the design of the optimal mechanism at Union level. Section 4 concludes.

\section{The Policy Background: the EMU Fiscal Framework}

The current European Monetary Union (EMU) fiscal framework is defined by the Stability and Growth Pact (SGP), by the Treaty on Stability Coordination and Governance (TSCG) - better known as 'Fiscal Compact' - and by secondary legislation which defines the implementation process. ${ }^{2}$ This framework imposes a number of constraints on member states' fiscal policy aggregates: budget deficit (both nominal and cyclically-adjusted), public debt and government spending. The main purpose is to ensure that national fiscal policies are conducted so as to lead to healthy public finances over the short and longer terms, in order to prevent the rising of negative spillover effects which might arise in a currency union where national fiscal positions are unbalanced. Specifically the framework includes two nominal constraints and a cyclically-adjusted one. First, nominal budget deficit must be less than $3 \%$ of the GDP every year. Second, debt-to-GDP ratio must converge to $60 \%$ with given yearly steps. ${ }^{3}$ Finally, cyclically-adjusted budget deficit must converge to the country-specific Medium-Term Objective (MTO) with given yearly steps. ${ }^{4}{ }^{5}$ Deviations from those targets are tolerated if a member state experiences severe downturns, catastrophic events, or has been implementing major structural reforms able to yield long-term positive budgetary effects and raise potential

\footnotetext{
${ }^{2}$ SGP has been formulated in 1997 (art.121 of the Treaty on the Functioning of the European Union) and has been implemented for the first time in 1999. It has been subsequently modified in 2005 and 2011. TSCG has been signed in March 2012 by all EU Member States except Czech Republic and the United Kingdom. Concerning the secondary legislation, see Regulation 1175/2011 and Regulation 1177/2011.

3 The step - calculated over a three year period (either backward or forward, according to the most favorable one) - is the $5 \%$ of the difference between the actual debt-to-GDP ratio and the $60 \%$ level.

${ }^{4}$ The step has been initially set at $0.5 \%$ of GDP. However the EU Commission has later decided to make it contingent on the state of the cycle (European Commission [2015]).

${ }^{5} \mathrm{~A}$ further nominal target is imposed: the rate of growth of public spending that is not matched by corresponding revenue increases - excluding interest payments and cyclical automatic changes in unemployment benefits - must not exceed the rate of growth of potential output. In order not to penalize investments, that component is averaged over four years. This last prescription is a further deficit-reducing measure. It has been designed to strengthen the control on government spending and avoid prociclicality.
} 
growth (European Commission [2015]).

At the beginning of each year $t$, member states must submit Stability Programmes (SP) reporting the budgetary framework from year $t-1$ up to year $t+3$, so that the compliance with the whole above-described set of constraints can be assessed by EU authorities. Macroeconomic and budgetary forecasts are made at the national level - either by the government or by independent bodies - but must be compared with the most recent forecasts performed by the EU Commission, which ultimately prevail in case of divergences. The EU Commission provides an ex-post assessment for year $t-1$, an in-year assessment for the year $t$ on the basis of in-year estimates, and an ex-ante evaluation for the year $t+1 .{ }^{6}$ Commission's evaluations are handed over to member states before the end of time $t$. If a member state's in-year or ex-ante evaluations are not in line with the rules along any of the above dimensions of constraints - and if they do not fall into the exceptional circumstances previously described - the Commission invites the member state to revise its budget-policies. If, instead, at time $t$ a member state fails the ex-post assessment on the $t-1$ fiscal policy framework, a fine is possibly imposed until the violation is corrected.

The MTO, introduced in the 2011 reform of fiscal governance, is defined as a structural budget deficit, namely in cyclically-adjusted terms, net of one-off and other temporary measures ${ }^{7}$, and it is defined as follows:

$$
D_{t}{ }^{C A}=D_{t}+\varepsilon^{D Y}\left(Y_{t}-Y_{t}^{*}\right)
$$

where $D_{t}$ denotes nominal budget deficit, $Y_{t}$ denotes nominal output, $Y_{t}^{*}$ represents potential output, and $\varepsilon^{D Y}$ is the semi-elasticity of the budget deficit (as a ratio to aggregate output) to the business cycle. The semi-elasticity $\varepsilon^{D Y}$ measures the automatic non-discretionary change in nominal deficit-to-GDP ratio in response to output gap movements. It is computed as the weighted difference between the elasticities of, respectively, revenue-to-GDP and expenditure-to-GDP to output, where the weights are given by the tenyears moving averages of output shares of revenue and expenditure. From (1), $D_{t}^{C A}$ - the target of MTO - crucially depends on $\varepsilon^{D Y}$ and $Y_{t}^{*}$. While the former is estimated with standard techniques from official data, the estimation of the latter is affected by some problems. The EU Council of July 2002 establishes that the reference method for the estimation of member states' potential output is the 'production function approach'. This method computes potential output on the basis of a standard technology-augmented CobbDouglas production function with constant returns to scale on potential capital $K$ and labour $L$ (Denis et al. [2002], Roeger [2006]). Technology is estimated through a bivariate Kalman Filter that exploits the link between its cyclical component and the degree of capacity utilization measured using the Capacity Utilization

\footnotetext{
${ }^{6} \mathrm{~A}$ qualitative assesment is made for the years $t+2$ and $t+3$.

${ }^{7}$ Examples of such measures are sales of non-financial assets, receipts of auctions of public owned licenses, tax amnesties, etc..
} 
Indicator (only available for the manufacturing sector) and the Business Survey Capacity Indicator (collected for the manufacturing sector, the construction sector, and services as part of the EU Commission's Business and Consumer Survey Programme). Potential capital stock, measured by the perpetual inventory method, corresponds to its actual value, under the assumption of full utilization of the existing stock. The capital is extrapolated in the out-of-sample period according to a given profile of productive investment (estimated through an $\mathrm{AR}(2)$ process) and assuming a constant depreciation rate (Cacciotti et al. [2014]). As for potential labour, it is calculated by a Kalman filter estimation of country-specific NAWRU, where the trend component is a random walk with drift, and the cyclical component is given by a Phillips Curve which relates the change in wage inflation to the unemployment rate and other exogenous variables such as terms of trade and wage share.

Although such a procedure is in line with the literature on the topic, it reveals that pinning down the true full-resources-utilization output level and, therefore, the output gap, is at least doubtful. More importantly, the estimation procedure requires calibration of several parameters whose choice is discretionary and to whom final results are extremely sensitive. It is important to stress that such a choice - in terms of priors and forecasts - is ultimately up to the EU Commission. The structural budget deficit - computed as in (1) must converge to the country-specific MTO, which is the lowest - i.e., the most ambitious - between three alternative thresholds whose computation is updated every three years. More specifically:

$$
M T O=\max \left\{D_{I L D}^{C A}, D_{M B}^{C A}, 1 \%\right\}
$$

In (2), $D_{I L D}^{C A}$ denotes the value of the structural deficit that ensures the convergence of debt-to-GDP ratio towards a 'sustainable' level once explicit and implicit liabilities (such as ageing costs) are taken into account. ${ }^{8}$ $D_{M B}^{C A}$ denotes the threshold value that ensures the respect of the $3 \%$ nominal reference under normal cyclical conditions, and is computed by adjusting the 3\% deficit-to-GDP ratio for the effect of a 'EU-representative' cyclical fluctuations. Finally, the last term in (2) is the framework's upper-bound member states agreed upon.

By 2015, the EU fiscal framework also links the convergence speed towards the MTO to cyclical conditions - given by the magnitude and sign of the output gap - and debt-to-GDP ratio (EU Commission [2015]). This novelty further strengthens the countercyclical nature of fiscal rules.

To sum up, cyclically-adjusted fiscal rules present both opportunities and risks. On the one hand, they exploit countries' true fiscal stance, irrespective of business cycle fluctuations. Hence, they induce counter-

\footnotetext{
${ }^{8}$ More specifically, $D_{I L D}^{C A}$ is the sum of three components: (a) the value that stabilizes the debt-to-GDP ratio at $60 \%$ under the forecasted average nominal growth for 2010-2060, (b) the value that covers one third of the present value of the projected increase in age-related expenditure, and (c) a supplementary debt-reduction effort were the country's debt-to-GDP ratio to be above $60 \%$.
} 
cyclical national fiscal policies, whose desirability has been widely discussed in the literature (Siu [2004], Galì and Monacelli [2005], Manasse [2007], and Ferrero [2009]). They aim at generating a structurally balanced budget for member states, while providing them with a safety margin (up to the $3 \%$ limit) to expand the budget in response to negative output fluctuations, and viceversa (see Andres and Domenech [2006]). On the other hand, cyclically-adjusted rules require rigorous calculation and estimation of latent variables that are unobservable both ex-ante and ex-post. Marcellino and Musso [2011] and Tereanu et al. [2014] document the mistakes in fiscal policy prescriptions due to the unreliability of potential output estimation. Cottarelli [2015] notes that, because the capital stock is derived as the sum of past investments that, in turn, are the most cyclical component of aggregate demand, it might reflect past demand conditions rather than the structural supply features of an economy. As described in the previous section, in this paper we take the view that potential output is determined by the 'effectiveness' of past structural investments made by national governments. This, we argue, gives an informational advantage to a member state's government with respect to the EMU's decision-making body over the estimate of the member states' potential output.

\section{The Model}

Our economy is populated by two countries $S_{i}$, for $i=1,2$. The two countries belong to a monetary union $(M U)$ that acts through an independent decision-making body. Each country finances public expenditures by recurring to both taxes and competitive financial outside investors. For the sake of simplicity, we normalize taxes to zero. ${ }^{9}$ Hence, in our simplified framework, public expenditures correspond to (primary) deficit $D_{i} \in[0,+\infty)$, for $i=1,2$. Although $D_{i}$ can in principle take negative values - in which case it represents a surplus - the normalization of taxes to zero allows us to focus on positive values only.

$D_{i}$ delivers a high return $Y\left(D_{i}\right) \in[\underline{Y},+\infty)$ with probability $p\left(\theta_{i}\right)$, and a low return $\underline{Y}$ with probability $1-p\left(\theta_{i}\right)$, where $Y\left(D_{i}\right)$ is increasing and concave, with $Y(0)=\underline{Y} \geq 0$, and where $\theta_{i} \in\{\underline{\theta}, \bar{\theta}\}$, with $\bar{\theta}>\underline{\theta}$, for $i=1,2 .{ }^{10}$ For instance, $\underline{Y}$ can be interpreted as the salvage value of assets in case of bankruptcy net of any pre-existing debt. The parameter $\theta_{i}$ represents $S_{i}$ 's ouput gap, i.e., the difference between $S_{i}$ 's current real output $Y_{i, 0}$, and its potential output $Y_{i}^{P}$, for $i=1,2 .{ }^{11}$ The current real output $Y_{i, 0}$ is exogenously given and observable by all the players. Potential output is unobservable to $M U$ and, therefore, so is the output gap. $M U$ attaches probability $\alpha_{i}$ to $\theta_{i}=\bar{\theta}$, and $1-\alpha_{i}$ to $\theta_{i}=\underline{\theta}$, for $i=1,2$. For the sake of simplicity,

\footnotetext{
${ }^{9}$ Our normalization implies that $M U$ 's member states invest all the collected taxes. This assumption deserves some qualification. In the presence of asymmetric information between $M U$ and $S_{i}$, for $i=1,2$, taxes can be modeled as cash-in-hand and, therefore, may function as a signalling device. However, differently from models of corporate financing, $S_{i}$ 's government may fail to fully internalize taxes expenditure. In this case, taxes function poorly as a signalling device.

${ }^{10}$ Because we consider $D_{i} \in[0,+\infty)$, for $i=1,2$, we also consider $\underline{Y} \geq 0$.

${ }^{11}$ Notice that, because we analyze a 1-period (dynamic) framework (see below), we can interpret $Y(D)$ as either output realization or output growth rate. This is also true of the variable $D$, which can be intepreted as either debt or deficit.
} 
we assume that $\theta_{i}$ 's probability distribution is independent of $Y_{i, 0} \cdot{ }^{12}$ We further assume that $\theta_{i}$ is perfectly observable by $S_{i}$. This assumption captures a framework in which $\theta_{i}$ is also unobservable to $S_{i}$, but whose prior distribution is more informative than $M U^{\prime}$ 's one.

Utility Functions. $S_{i}$ 's utility function is given by:

$$
U_{i}\left(\theta_{i}, \delta_{i}\right)=\left[p\left(\theta_{i}\right) Y\left(D_{i}\right)+\left(1-p\left(\theta_{i}\right)\right)\left(\underline{Y}+t_{j}\right)\right]-\delta_{i}\left[p\left(\theta_{i}\right)\left(Y_{L, i}+t_{i}\right)+\left(1-p\left(\theta_{i}\right)\right) \min \left\{Y_{L, i}+t_{i}, \underline{Y}+t_{j}\right\}\right]
$$

$\forall \theta_{i}$, where $Y_{L, i} \in\left[0, Y\left(D_{i}\right)\right]$ is the return accruing to perfectly competitive lenders, and where $t_{i} \geq 0$ represents a net transfer from $S_{i}$ to $S_{j}$, for $i, j=1,2$ and $i \neq j .{ }^{13}$ The parameter $\delta_{i} \in(0,1]$, for $i=1,2$, denotes $S_{i}$ 's discounting of the cost of debt. For instance, $\delta_{i}<1$ captures the shortsightedness of $S_{i}$ 's government.

The first term in square brackets in (3) represents the expected realization of output as a function of $S_{i}$ 's type $\left(\theta_{i}\right)$ and investment $\left(D_{i}\right)$, while the second term in square brackets represents the discounted expected payment to lenders. Notice that both the expected output and the marginal benefit of $D_{i}$ are increasing in $\theta_{i}$ : the higher $S_{i}$ 's output gap - or, similarly, the higher $S_{i}$ 's potential output - the higher the multiplier of public investments. The idea that the size of the multipliers of government spending depends on the output gap is supported by solid contributions on both the theoretical and the empirical sides. From the theoretical viewpoint, Christiano et al. [2009] and Woodford [2010], among others, note that the spending multiplier is higher during recessions because the economy is most likely to reach the zero lower bound on the nominal interest rate. ${ }^{14}$ In particular, the proportionality between slack capacity and output effects of the government spending stimulus comes from the fact that, because of the higher output gap, the government-spendinginduced increase in output translates into a lower rise in inflation due to the flatter marginal cost curve which prevails under a great deal of excess capacity. This makes it easier for central banks to maintain a constant real interest rate even in face of an aggregate demand stimulus. This intuition is empirically confirmed and fairly robust to alternative estimation techniques. Auerbach and Gorodnichenko [2012a] employ a regime-switching structural VAR (SVAR) with smooth transition across states, where the threshold variable is exogenously determined. ${ }^{15}$ The authors estimate a quarterly data model (1947-2009) for the US and find that the output

\footnotetext{
${ }^{12}$ One may think of a framework in which an extremely high (low) realization of $Y_{i, 0}$ determines a lower (higher) value of $\alpha_{i}$.

${ }^{13}$ More specifically, $t_{i}$ represent a transfer from $S_{i}$ to $M U$, which further redistributes it to $S_{j}$, for $i, j=1,2$ and $i \neq j$. $t_{i} \geq 0$ represents a limited liability constraint preventing $M U$ from allocating to countries more money than the amount received from them.

${ }^{14}$ See also Manasse [2007].

${ }^{15}$ More specifically, Auerbach and Gorodnichenko [2012a] use a moving average representation of the GDP growth rate.
} 
effect of government spending is considerably larger during a recession rather than during an expansion. Auerbach and Gorodnichenko [2012b] and Batini et al. [2012] obtain similar results by looking at a larger sample of OECD countries. Baum et al. [2012] adopt a non-linear threshold VAR and - more importantly for our purposes - use output gap (rather than GDP growth) to define the cycle and better identify business fluctuations (see also Harding and Pagan [2002]). They investigate six of the G7 economies from the 1970s to 2011 and find that in all cases the magnitude of the multiplier size is increasing with the negative output gap.

$M U$ 's utility function is given by:

$$
V=\sum_{i=1}^{2} \alpha_{i} U_{i}(\underline{\theta}, 1)+\left(1-\alpha_{i}\right) U_{i}(\bar{\theta}, 1) .
$$

$M U$ 's objective function differs from $S_{i}$ 's one because of $(i)$ the aggregation of $U_{1}$ and $U_{2}$ (each with the same weight), and $(i i)$ the absence of discounting of the cost of debt, i.e., $\delta_{M U}=1$. The pair $\left\{t_{1}, t_{2}\right\}$ of net transfers among member states does not directly affect $M U$ 's utility.

Simplifying Assumptions. In the following, we simplify our framework by assuming that $\alpha_{1}=1$. Let us further simplify our model by assuming that $p_{1}=1 .{ }^{16}$ Country $S_{1}$ 's type is then known to all the players, and $S_{1}$ is such that it always realizes a high return $Y\left(D_{1}\right)$ from its investment $D_{1}$.

Financial Market. The lending market is competitive. Because $S_{1}$ and $S_{2}$ are part of $M U$, lenders anticipate that bail-out by one member state towards another one can occur, provided sufficient funds are available at the $M U$-level. ${ }^{17}$ Given our simplifying assumptions, bail-out can possibly occur from $S_{1}$ to $S_{2}$. The lenders' break-even constraints for $S_{1}$ and $S_{2}$ are given by:

$$
\begin{gathered}
Y_{L, 1} \geq D_{1}, \\
p\left(\theta_{2}\right) Y_{L, 2}+\left(1-p\left(\theta_{2}\right)\right)\left\{\min \left[Y_{L, 2}, \underline{Y}\right]+\min \left[Y\left(D_{1}\right)-Y_{L, 1}, Y_{L, 2}-\underline{Y}\right] \times 1\left\{Y_{L, 2}>\underline{Y}\right\}\right\} \geq D_{2},
\end{gathered}
$$

respectively, where the $E$ denotes the expectaction operator, and where $1\left\{Y_{L, 2}>\underline{Y}\right\}$ is an indicator function that takes value 1 when $Y_{L, 2}>\underline{Y}$, and takes value 0 otherwise. Notice that the transfer $t_{2}$ does not enter (6) because we assume that debt repayment $Y_{L, 2}$ is senior with respect to $t_{2}$. Moreover, given our assumption on $S_{1}$, we anticipate that $(i) t_{1}=0$ and $(i i) S_{1}$ is able to fully repay its debt $D_{1}$.

\footnotetext{
${ }^{16}$ The assumption $p\left(\theta_{1}\right)=1$ does not necessarily imply that $p\left(\theta_{2}\right)=1$ when $\theta_{2}=\bar{\theta}$. This assumption is made to simplify computations only.

${ }^{17}$ In our model, bail-out generates externalities among member states. On national governments' shortsighedness and externalities within a monetary union, see Cukierman et al. [1992], Roubini and Sachs [1989], Alesina and Tabellini [1990], Tabellini and Alesina [1990], Beetsma and Bovenberg [1999], and Manasse [2007].
} 
Timing. We analyze a one-period dynamic game. At the beginning of the period, Nature draws $\theta_{2}$, and this is perfectly revealed to $S_{2}$ only. $M U$ then post contracts. More specifically, $M U$ sets $D_{1}^{M U}$ and designs a mechanism $\left\{t\left(\theta_{2}\right), D^{M U}\left(\theta_{2}\right)\right\}$, for $\theta_{2} \in\{\underline{\theta}, \bar{\theta}\}$. Given $D_{1}^{M U}$ and $\left\{t\left(\theta_{2}\right), D^{M U}\left(\theta_{2}\right)\right\}, S_{i}$ borrows $D_{i}$ from competitive lenders, for $i=1,2$. Finally, output realizes, lenders gets repayment and transfers $t_{i}$ are made, for $i=1,2$. Our solution concept is Perfect Bayesian Equilibrium (PBE).

In the following, we assume that $M U$ can fully restrict $S_{i}$ 's choice of $D_{i}$ to the proposed mechanism: this is equivalent to a situation in which $S_{i}$ incurs a sufficiently high penalty were it to violate the terms of the proposed mechanism.

We proceed by first investigating the solution to both $S_{i}$ 's and $M U$ 's problems under complete information about $\theta_{2}$, for $i=1,2$.

\subsection{The Benchmark: Complete Information}

Suppose $\theta_{2}$ is perfectly observable by all the parties. We first study $S_{i}$ 's optimal decentralized choice of $D_{i}$ given it belong s to $M U$, for $i=1,2 . S_{1}$ solves the following constrained maximization problem:

$$
\begin{array}{r}
\max _{\left\{D_{1}\right\}} Y\left(D_{1}\right)-\delta_{1} Y_{L, 1}, \\
\text { s.t. } Y_{L, 1}=D_{1} .
\end{array}
$$

$S_{2}$ solves:

$$
\begin{aligned}
& \max _{\left\{D_{2}\right\}}\left[p\left(\theta_{2}\right) Y\left(D_{2}\right)+\left(1-p\left(\theta_{2}\right)\right) \underline{Y}\right]-\delta_{2}\left[p\left(\theta_{2}\right)\left(Y_{L, 2}+t_{2}\right)+\left(1-p\left(\theta_{2}\right)\right) \min \left\{Y_{L, 2}+t_{2}, \underline{Y}\right\}\right], \\
\text { s.t. } & p\left(\theta_{2}\right) Y_{L, 2}+\left(1-p\left(\theta_{2}\right)\right)\left\{\min \left[Y_{L, 2}, \underline{Y}\right]+\min \left[Y\left(D_{1}\right)-Y_{L, 1}, Y_{L, 2}-\underline{Y}\right] \times 1\left\{Y_{L, 2}>\underline{Y}\right\}\right\}=D_{2} .
\end{aligned}
$$

The solution to $S_{1}$ 's problem in (7) is given by the first-order conditions(FOC):

$$
Y^{\prime}\left(\hat{D}_{1}\right)=\delta_{1}
$$

The solution to $S_{2}$ 's problem in (8) depends on $D_{2}$. If $D_{2} \leq \underline{Y}$, one can check that $Y_{L, 2}=D_{2}<\underline{Y}$. In this case, $S_{2}$ is able to pay its own debt independently of the realized state of nature. If $D_{2}>\underline{Y}$ instead, provided $\min \left[Y\left(D_{1}\right)-Y_{L, 1}, Y_{L, 2}-\underline{Y}\right]=Y_{L, 2}-\underline{Y}$, from the lenders' break-even constraint we obtain $Y_{L, 2}=D_{2}>\underline{Y}$, that implies the following first-order condition to the problem in (8): 


$$
Y^{\prime}\left(\hat{D}_{2}\right)=\delta_{2}
$$

Because $\min \left[Y\left(D_{1}\right)-Y_{L, 1}, Y_{L, 2}-\underline{Y}\right]=Y_{L, 2}-\underline{Y}, S_{1}$ is able to provide full coverage for $S_{2}$ 's debt if a bad state of nature realizes $\left(Y\left(D_{2}\right)=\underline{Y}\right) \cdot{ }^{18}$ Therefore, the investment optimally chosen by $S_{2}$ is independent of its type $\theta_{2}$.

In the following we assume that the pair $\left\{\hat{D}_{1}, \hat{D}_{2}\right\}$ is such that $\min \left[Y\left(\hat{D}_{1}\right)-\hat{D}_{1}, \hat{D}_{2}-\underline{Y}\right]=\hat{D}_{2}-\underline{Y}$, where $\hat{D}_{2}>\underline{Y}$ and - from the lenders' break-even constraint $-Y_{L, i}=\hat{D}_{i}$, for $i=1,2$.

We now analyze $M U$ 's optimal choice of $D_{i}$, for $i=1,2$. From (4), $M U$ solves:

$$
\max _{\left\{D_{1}, D_{2}\right\}} \sum_{i=1}^{2} p\left(\theta_{i}\right) Y\left(D_{i}\right)+\left(1-p\left(\theta_{i}\right)\right) \underline{Y}-D_{i},
$$

where we have substituted the constraints (5) and (6) into the objective function, and where $Y_{L, i}=D_{i}$, for $i=1,2$. The FOCs to this problem are given by:

$$
p\left(\theta_{i}\right) Y^{\prime}\left(D_{i}^{*}\right)=1, \text { for } i=1,2 .
$$

By comparing (9) and (10) with (12), it is easily seen that the solution to $M U$ 's problem $D_{i}^{*}\left(\theta_{i}\right)$ is weakly lower than $\hat{D}_{i}\left(\theta_{i}, \delta_{i}\right)$, for $i=1,2$. More specifically, we have $D_{1}^{*} \leq \hat{D}_{1}\left(\delta_{1}\right)$ and $D_{2}^{*}(\underline{\theta})<D_{2}^{*}(\bar{\theta})<\hat{D}_{2}\left(\delta_{2}\right)$.

To sum up, both $S_{1}$ and $S_{2}$ tend to inefficiently over-borrow because of their government's shortsightedness. Moreover, potential bail-out further induces $S_{2}$ to inefficiently over-borrowin the financial market. $M U$ internalizes the potential bail-out by $S_{1}$ and sets an efficient investment that is increasing in $S_{2}$ 's ability to generate a high return, i.e., $S_{2}$ 's deficit level increases with its potential output (output gap).

In order to focus on the most interesting scenario, in the following we set $D_{2}^{*}(\underline{\theta})>\underline{Y}$.

\subsection{Borrowing Under Asymmetric Information}

We now turn to the analysis of the case in which there is asymmetric information over the value of $\theta_{2}$. Let us define $p(\bar{\theta}) \equiv \bar{p}$ and $p(\underline{\theta}) \equiv \underline{p}$, where $\Delta p \equiv \bar{p}-\underline{p}>0$.

The lenders' break-even constraint with respect to $S_{2}$ is now given by:

$[\alpha \bar{p}+(1-\alpha) \underline{p}] Y_{L, 2}+[\alpha(1-\bar{p})+(1-\alpha)(1-\underline{p})]\left\{\min \left[Y_{L, 2}, \underline{Y}\right]+\min \left[Y\left(D_{1}\right)-Y_{L, 1}, Y_{L, 2}-\underline{Y}\right] \times 1\left\{Y_{L, 2}>\underline{Y}\right\}\right\} \geq D_{2}$.

Because of bail-out, (13) is rewritten as:

\footnotetext{
${ }^{18}$ Our main results hold also when $\min \left[Y\left(D_{1}\right)-Y_{L, 1}, Y_{L, 2}-\underline{Y}\right]=Y\left(D_{1}\right)-Y_{L, 1}$. We focus on the case that makes it easier to carry computations out.
} 


$$
Y_{L, 2} \geq D_{2}
$$

From (14), we immediately have that, in a decentralized solution, $S_{2}$ sets $\hat{D}_{2}\left(\delta_{2}\right)$ independently of its type $\theta_{2}$. Unlike in standard models of adverse selection, in the presence of bail-out neither lenders have incentives in designing a mechanism to discriminate between types of borrowers, nor borrowers have an incentive in separating themselves through signalling. ${ }^{19}$ In our framework, we show that $M U$ is interested in discriminating between different types of borrowers because of the inefficient over-borrowing arising under asymmetric information.

Consider then the case in which $M U$ is able to restrict (e.g., put a cap to) $S_{1}$ and $S_{2}$ 's borrowing choices. $M U$ sets $D_{1}^{*}$ for $S_{1}$. Also, suppose $M U$ proposes $S_{2}$ the pair $\left\{\underline{D}^{*}, \bar{D}^{*}\right\}$, where $D^{*}(\underline{\theta}) \equiv \underline{D}^{*}$ and $D^{*}(\bar{\theta}) \equiv \bar{D}^{*}$. Because of bail-out, we have that $Y_{L, 2}\left(D_{2}\right)=D_{2}$ independently of $S_{2}$ 's choice between $\underline{D}^{*}$ and $\bar{D}^{*}$.

Let us define $\tilde{\theta}_{2}$ as $S_{2}$ 's report of its type $\theta_{2} . S_{2}$ 's utility when $\theta_{2}=\underline{\theta}$ and it reports its true type $\left(\tilde{\theta}_{2}=\underline{\theta}\right)$ is given by:

$$
U_{2}(\underline{\theta}, \underline{\theta})=\left[\underline{p} Y\left(\underline{D}^{*}\right)+(1-\underline{p}) \underline{Y}\right]-\delta_{2}\left[\underline{p}^{*}+(1-\underline{p}) \underline{Y}\right]
$$

while $S_{2}$ 's utility when $\theta_{2}=\underline{\theta}$ and it falsely reports $\tilde{\theta}_{2}=\bar{\theta}$ is given by:

$$
U_{2}(\underline{\theta}, \bar{\theta})=\left[\underline{p} Y\left(\bar{D}^{*}\right)+(1-\underline{p}) \underline{Y}\right]-\delta_{2}\left[\underline{p} \bar{D}^{*}+(1-\underline{p}) \underline{Y}\right]
$$

The $\underline{\theta}$-type has an incentive to mimic the $\bar{\theta}$-type and borrow $\bar{D}^{*}$ if:

$$
U_{2}(\underline{\theta}, \underline{\theta})<U_{2}(\underline{\theta}, \bar{\theta}) \Longleftrightarrow Y\left(\underline{D}^{*}\right)-\delta_{2} \underline{D}^{*}<Y\left(\bar{D}^{*}\right)-\delta_{2} \bar{D}^{*}
$$

The inequality in (17) holds because $\underline{D}^{*}<\bar{D}^{*}<\hat{D}_{2}$, where $\hat{D}_{2}=\arg \max D_{2}\left[Y\left(D_{2}\right)-\delta_{2} D_{2}\right]$.

To sum up, if $M U$ were to propose the pair $\left\{\underline{D}^{*}, \bar{D}^{*}\right\}$, the type $\theta_{2}=\underline{\theta}$ finds it profitable to mimic the type $\bar{\theta} \cdot{ }^{20}$

\subsection{Fiscal Rules Under Asymmetric Information}

$M U$ 's objective is to implement the most efficient choice of $D_{2}$ contingent on the asymmetric information problem. We investigate the possibility to build a mechanism to discriminate between the two types of country $S_{2}$. $M U$ puts in place a mechanism $\left\{\left(t_{2}(\underline{\theta}), D_{2}(\underline{\theta})\right),\left(t_{2}(\bar{\theta}), D_{2}(\bar{\theta})\right)\right\} \cdot{ }^{21}$ Notice that, while $D_{2}$ is the quantity borrowed on the market at the beginning of the period, $t_{2}$ is a sum to be paid to $M U$ at the

\footnotetext{
${ }^{19}$ To rephrase it, the presence of (full) bail-out eradicates cross-subsidization between different types of borrowers.

${ }^{20}$ It is straightforward to verify that type $\theta_{2}=\bar{\theta}$ has no incentive to mimic the type $\underline{\theta}$.

${ }^{21}$ The revelation principle applies. Hence, we focus on direct revelation mechanisms.
} 
end of the period, i.e., after the realization of output is observed by all the parties.

The lump-sum transfer $t_{2}$ can be modeled as an (increase in the) interest rate paid by $S_{2}$ when borrowing money from the capital market. Intuitively, all else equal, because the $\bar{\theta}$-type's multiplier of public investments is higher than that of the $\underline{\theta}$-type, the $\bar{\theta}$-type may be willing than the $\underline{\theta}$-type to borrow more at a higher interest rate.

In the following we define $t_{2}(\underline{\theta}) \equiv \underline{t}_{2}, t_{2}(\bar{\theta}) \equiv \bar{t}_{2}, D_{2}(\underline{\theta}) \equiv \underline{D}_{2}$, and $D_{2}(\bar{\theta}) \equiv \bar{D}_{2}$. We first briefly discuss $S_{2}$ 's Individual Rationality Constraint $\left(I R_{\theta}\right)$, for $\theta \in\{\underline{\theta}, \bar{\theta}\}$. Suppose $S_{2}$ rejects the mechanism proposed by $M U$ and over-borrows on the financial market. In this case, financial and political penalties are typically imposed on $S_{2}$. In the following, we assume that penalties are sufficiently high to deter both types of $S_{2}$ from over-borrowing.

We start our analysis with $S_{2}$ 's Incentive Compatibility Constraint $(I C C)$. The $\underline{\theta}$-type's constraint $\left(I C C_{\underline{\theta}}\right)$ is given by:

$$
\begin{aligned}
& {\left[\underline{p} Y\left(\underline{D}_{2}\right)+(1-\underline{p}) \underline{Y}\right]-\delta_{2}\left[\underline{p}\left(Y_{L, 2}\left(\underline{D}_{2}\right)+\underline{t}_{2}\right)+(1-\underline{p}) \min \left\{Y_{L, 2}\left(\underline{D}_{2}\right)+\underline{t}_{2}, \underline{Y}\right\}\right]>} \\
& {\left[\underline{p} Y\left(\bar{D}_{2}\right)+(1-\underline{p}) \underline{Y}\right]-\delta_{2}\left[\underline{p}\left(Y_{L, 2}\left(\bar{D}_{2}\right)+\bar{t}_{2}\right)+(1-\underline{p}) \min \left\{Y_{L, 2}\left(\bar{D}_{2}\right)+\bar{t}_{2}, \underline{Y}\right\}\right],}
\end{aligned}
$$

while the $\bar{\theta}$-type's constraint $\left(I C C_{\underline{\theta}}\right)$ is given by:

$$
\begin{gathered}
{\left[\bar{p} Y\left(\bar{D}_{2}\right)+(1-\bar{p}) \underline{Y}\right]-\delta_{2}\left[\bar{p}\left(Y_{L, 2}\left(\bar{D}_{2}\right)+\bar{t}_{2}\right)+(1-\bar{p}) \min \left\{Y_{L, 2}\left(\bar{D}_{2}\right)+\bar{t}_{2}, \underline{Y}\right\}\right]>} \\
{\left[\bar{p} Y\left(\underline{D}_{2}\right)+(1-\underline{p}) \underline{Y}\right]-\delta_{2}\left[\bar{p}\left(Y_{L, 2}\left(\underline{D}_{2}\right)+\underline{t}_{2}\right)+(1-\bar{p}) \min \left\{Y_{L, 2}\left(\underline{D}_{2}\right)+\underline{t}_{2}, \underline{Y}\right\}\right] .}
\end{gathered}
$$

We proceed by distinguishing different cases depending on the value of the min-function within each constraint.

Case 1: $\underline{D}_{2}>\underline{Y}$. Because efficiency requires $\bar{D}_{2}>\underline{D}_{2}$, we also have $\bar{D}_{2}>\underline{Y}$. Given $Y_{L, 2}\left(D_{2}\right)=D_{2}$, for $D_{2} \in\left\{\underline{D}_{2}, \bar{D}_{2}\right\}$, we have $\min \left\{Y_{L, 2}\left(D_{2}\right)+t_{2}\left(D_{2}\right), \underline{Y}\right\}=\underline{Y}, \forall \theta_{2} \in\{\underline{\theta}, \bar{\theta}\}$. We can then write (18) and (19) as:

$$
\begin{aligned}
& \bar{t}_{2}-\underline{t}_{2}>v_{2}\left[Y\left(\bar{D}_{2}\right)-Y\left(\underline{D}_{2}\right)\right]-\left[\bar{D}_{2}-\underline{D}_{2}\right], \\
& \bar{t}_{2}-\underline{t}_{2}<v_{2}\left[Y\left(\bar{D}_{2}\right)-Y\left(\underline{D}_{2}\right)\right]-\left[\bar{D}_{2}-\underline{D}_{2}\right],
\end{aligned}
$$

respectively, where $v_{2}=\frac{1}{\delta_{2}}$. 
Because $v_{2} \geq 1$ and $Y\left(D_{2}\right) \geq D_{2}$, for $D_{2} \in\left\{\underline{D}_{2}, \bar{D}_{2}\right\}$, the right-hand side (RHS) in (20) and (21) is positive. From (20) and (21), it is easily shown that $M U$ cannot discriminate between types as long as it wishes to implement a pair of borrowing levels such that $\bar{D}_{2}>\underline{D}_{2}>\underline{Y}$. Intuitively - when $\bar{D}>\underline{D}>\underline{Y}-$ neither type of borrowers is affected by the transfers $\left(t_{2}\left(D_{2}\right)\right.$ ) when a bad state of nature realizes (with probability $\left.1-p\left(\theta_{2}\right)\right)$. As a consequence, only the good state of nature matters, irrespectively of the borrower's type. The presence of only one relevant state of nature removes the relative difference between the two types of borrower, that allows the discrimination between types in the first place. The irrelevance of one state of nature makes the choice between the two proposed mechanisms independent of the borrower's type.

Case 2: $\underline{D}_{2}<\underline{Y}<\bar{D}_{2}$. In this case, we can write the two constraints in (18) and (19) in the following way:

$$
\begin{aligned}
& \bar{t}_{2}-\underline{t}_{2}>v_{2}\left[Y\left(\bar{D}_{2}\right)-Y\left(\underline{D}_{2}\right)\right]-\left[\bar{D}_{2}-\underline{D}_{2}\right]-\frac{1-\underline{p}}{\underline{p}}\left[\underline{Y}-\min \left\{\underline{D}_{2}+\underline{t}_{2}, \underline{Y}\right\}\right], \\
& \bar{t}_{2}-\underline{t}_{2}<v_{2}\left[Y\left(\bar{D}_{2}\right)-Y\left(\underline{D}_{2}\right)\right]-\left[\bar{D}_{2}-\underline{D}_{2}\right]-\frac{1-\bar{p}}{\bar{p}}\left[\underline{Y}-\min \left\{\underline{D}_{2}+\underline{t}_{2}, \underline{Y}\right\}\right] .
\end{aligned}
$$

Because $\bar{p}>\underline{p}$, the RHS in (22) is lower than the RHS in (23), provided the last term in square brackets in both RHSs is strictly greater than zero. The last condition holds if $\underline{t}_{2}$ is sufficiently low and, in particular, it holds if $\underline{t}_{2}=0$. If this is the case, $M U$ can discriminate between the two types by appropriately designing transfers $\left\{\underline{t}_{2}, \bar{t}_{2}\right\}$. Unlike in Case 1, both states of nature are relevant and allow for the exploitation of $\bar{\theta}$-type's comparative advantage - over $\underline{\theta}$-type - in the expected realization of output.

Case 3: $\underline{D}_{2}<\bar{D}_{2}<\underline{Y}$. In this case, the two constraints in (18) and (19) can be written as:

$$
\begin{aligned}
& \bar{t}_{2}-\underline{t}_{2}>v_{2}\left[Y\left(\bar{D}_{2}\right)-Y\left(\underline{D}_{2}\right)\right]-\left[\bar{D}_{2}-\underline{D}_{2}\right]-\frac{1-\underline{p}}{\underline{p}}\left[\min \left\{\bar{D}_{2}+\bar{t}_{2}, \underline{Y}\right\}-\min \left\{\underline{D}_{2}+\underline{t}_{2}, \underline{Y}\right\}\right], \\
& \bar{t}_{2}-\underline{t}_{2}<v_{2}\left[Y\left(\bar{D}_{2}\right)-Y\left(\underline{D}_{2}\right)\right]-\left[\bar{D}_{2}-\underline{D}_{2}\right]-\frac{1-\bar{p}}{\bar{p}}\left[\min \left\{\bar{D}_{2}+\bar{t}_{2}, \underline{Y}\right\}-\min \left\{\underline{D}_{2}+\underline{t}_{2}, \underline{Y}\right\}\right] .
\end{aligned}
$$

As in Case 2, the RHS in (24) is lower than the RHS in (25) provided the last term in square brackets in both RHSs is strictly greater than zero. This last condition holds if $\underline{t}_{2}$ is sufficiently low and, in particular, it holds if $\underline{t}_{2}=0$. Therefore, in this case also it is possible to design transfers $\left\{\underline{t}_{2}, \bar{t}_{2}\right\}$ to separate the two types of borrower.

We now discuss the otpimal choice of $\underline{t}_{2}$. As discussed in Case $\mathbf{2}$ and Case 3, an equilibrium that discriminate between types requires a sufficiently low value of $\underline{t}_{2}$. 
Lemma 1. $M U$ optimally sets $\underline{t}_{2}^{*}=0$.

Proof. Consider Case 2 and Case 3. ${ }^{22}$ From (4), the transfer $t_{2}$ does not affect $M U$ 's utility. Hence, $M U$ 's objective is to design $\underline{t}_{2}$ so as to relax the borrower's $I C C$.

Consider Case 2. We can write the combination of (22) and (23) in the following way:

$$
X\left(\underline{t}_{2}\right)-\frac{1-\underline{p}}{\underline{p}} Z\left(\underline{t}_{2}\right)<\bar{t}_{2}<X\left(\underline{t}_{2}\right)-\frac{1-\bar{p}}{\bar{p}} Z\left(\underline{t}_{2}\right),
$$

where:

$$
\left\{\begin{array}{l}
X\left(\underline{t}_{2}\right) \equiv \underline{t}_{2}+v_{2}\left[Y\left(\bar{D}_{2}\right)-Y\left(\underline{D}_{2}\right)\right]-\left[\bar{D}_{2}-\underline{D}_{2}\right] \\
Z\left(\underline{t}_{2}\right) \equiv \underline{Y}-\min \left\{\underline{D}_{2}+\underline{t}_{2}, \underline{Y}\right\}
\end{array} .\right.
$$

From (26) and (27), both the left-hand side (LHS) and RHS are increasing in $\underline{t}_{2}$. Since $\frac{\partial L H S}{\partial \underline{t}_{2}} \geq \frac{\partial R H S}{\partial \underline{t}_{2}}$, by decreasing $\underline{t}_{2} M U(i)$ makes it possible to design a mechanism that discriminates between types of borrower - i.e., it ensures that $\left(X\left(\underline{t}_{2}\right)-\frac{1-\underline{p}}{\underline{p}} Z\left(\underline{t}_{2}\right), X\left(\underline{t}_{2}\right)-\frac{1-\bar{p}}{\bar{p}} Z\left(\underline{t}_{2}\right)\right)$ is not an empty set - and $(i i)$ enlarges the values of $\bar{t}_{2}$ such that a separating equilibrium exists. Hence, $M U$ sets $\underline{t}_{2}^{*}=0$. A very close reasoning establishes that $\underline{t}_{2}^{*}=0$ is also optimal in Case 3 .

Having established the optimal value for $\underline{t}_{2}$, we can now turn to $M U$ 's choice of $\left\{\underline{D}_{2}, \bar{D}_{2}\right\}$. First, notice that all the three cases above-analyzed rely on the following feasibility constraints:

$$
\begin{aligned}
& \bar{t}_{2}<Y\left(\bar{D}_{2}\right)-\bar{D}_{2}, \\
& \underline{t}_{2}<Y\left(\underline{D}_{2}\right)-\underline{D}_{2},
\end{aligned}
$$

that ensure the feasibility of the transfer required by $M U$ when a good state of nature realizes.

From (4), because transfers do not directly affect $M U$ 's utility, it is easily seen that $M U$ aims at implementing borrowing levels which are as close as possible to the efficient solution $\left\{D_{2}^{*}(\underline{\theta}), D_{2}^{*}(\bar{\theta})\right\}$.

Proposition 1. Provided $\delta_{2}$ is sufficiently high, $M U$ implements the efficient solution $\left\{D_{2}^{*}(\underline{\theta}), D_{2}^{*}(\bar{\theta})\right\}$ if $D_{2}^{*}(\underline{\theta})<\underline{Y}$. If $D_{2}^{*}(\underline{\theta}) \geq \underline{Y}$ instead, $M U$ implements a second-best solution $\left\{D_{2}^{S B}(\underline{\theta}), D_{2}^{S B}(\bar{\theta})\right\}$, where $D_{2}^{S B}\left(\underline{\theta}, \delta_{2}\right)<\underline{Y}<D_{2}^{*}(\underline{\theta})$ and $D_{2}^{S B}(\bar{\theta})=D_{2}^{*}(\bar{\theta})$.

\footnotetext{
${ }^{22}$ We disregard Case 1 because $M U$ cannot discriminate between the two types of borrowers.
} 
Proof. Disregard first (28) and (29). Suppose $M U$ implements some pair $\left\{D_{2}(\underline{\theta}), D_{2}(\bar{\theta})\right\}$. From (4), $M U$ 's unconstrained choice is also equal to the first-best choice $\left\{D_{2}^{*}(\underline{\theta}), D_{2}^{*}(\bar{\theta})\right\}$ as computed in (12). In the presence of asymmetric information, $M U$ can implement $\left\{D_{2}^{*}(\underline{\theta}), D_{2}^{*}(\bar{\theta})\right\}$ provided $D_{2}^{*}(\underline{\theta})<\underline{Y}$. In fact, from the two pairs of inequalities (22)-(23) and (24)-(25) and from Lemma 1, there exists some $\vec{t}_{2}^{*}>0$ such that all the relevant Incentive Constraints hold.

Suppose $D_{2}^{*}(\underline{\theta}) \geq \underline{Y}$ instead. In this case, from (20) and (21), the pair $\left\{D_{2}^{*}(\underline{\theta}), D_{2}^{*}(\bar{\theta})\right\}$ does not allow $M U$ to discriminate between types of $S_{2}$. $M U$ then sets $D_{2}^{S B}(\underline{\theta})=\underline{Y}-\varepsilon$ and $D_{2}^{S B}(\bar{\theta})=D^{*}(\bar{\theta})$, for $\varepsilon>0$ as small as one likes. The downward distortion to $D_{2}(\underline{\theta})$ allows $M U$ to design an appropriate transfer $\left\{\underline{t}_{2}^{S B} \bar{t}_{2}^{S B}\right\}$, where $\underline{t}_{2}^{S B}=0$ (from Lemma 1) and $\bar{t}_{2}^{S B}$ verifies (22) and (23).

Finally, let us verify the inequalities in (28) and (29). The second inequality holds because $\underline{t}_{2}^{*}=0$. Concerning the first inequality in (28), from (22) it is easily seen that the implied lowerbound on $\bar{t}_{2}$ does not exceed the upperbound implied by (28) as long as $v_{2}$ takes a value sufficiently close to 1 , i.e., as long as $\delta_{2}$ is sufficiently close to 1 , and viceversa.

Finally, suppose that $M U$ wishes to implement $\underline{D}_{2}=\underline{Y}-\varepsilon<D_{2}^{*}(\underline{\theta})$ and $\bar{D}_{2}=D^{*}(\bar{\theta})$, for $\varepsilon>0$ as small as one likes, but $\delta_{2}$ is such that the feasibility constraint in (28) does not hold. In this case, whether $M U$ can implement a mechanism that discriminates among types of $S_{2}$ while verifying all the relevant constraints crucially depends on the value of $\bar{p}$. From (25) and (28), the feasibility constraint holds if:

$$
\left(v_{2}-1\right)\left[Y\left(\bar{D}_{2}\right)-\bar{D}_{2}\right]-v_{2}\left[Y\left(\underline{D}_{2}\right)-\underline{D}_{2}\right]-\frac{1-\bar{p}}{\bar{p}}\left[\underline{Y}-\underline{D}_{2}\right]<0 .
$$

Because we are analyzing the case in which $\underline{D}_{2}<\underline{Y}<D^{*}(\underline{\theta})$, we have that $Y^{\prime}\left(\underline{D}_{2}\right)>1$. Therefore, whether the LHS in (30) is decreasing in $\underline{D}_{2}$ at $\underline{D}_{2}=\underline{Y}-\varepsilon$ depends on the value of $\bar{p}$. Provided $\underline{D}_{2}=\underline{Y}-\varepsilon$ does not verify the feasibility constraint in (28), for sufficiently low values of $\bar{p}, M U$ can further distort downward $\underline{D}_{2}$ to meet the feasibility constraint.

Intuitively, $M U$ acts as a social planner and, as such, is interested in maximizing efficiency. $M U$ internalizes the externalities created by potential bail-out among member states, and it design a mechanism to correct the distorted incentives created by the presence of bail-out and asymmetric information overmember states' potential output. Transfers sole function is to achieve efficiency rather than extract surplus from member countries. First, this logic explains why $M U$ sets $\underline{t}_{2}^{*}=0$. Second, it explains why $M U$ introduces 'no distortion at the top' when $D^{*}(\underline{\theta}) \geq \underline{Y}$, i.e., when the first-best efficient solution is not implementable by resorting to transfers only. If $D^{*}(\underline{\theta}) \geq \underline{Y}$, in order to discriminate between types $M U$ introduces the smallest possible distortion in $D_{2}(\theta)$, for $\theta_{2} \in\{\underline{\theta}, \bar{\theta}\}$. No distortion in $D^{*}(\bar{\theta})$ is introduced because $D_{2}(\bar{\theta})$ only affects the transfers needed to sustain the equilibrium. A downward distortion to $D_{2}(\underline{\theta})$ is introduced 
so as to allow $M U$ to exploit the relative difference in the types' expected realization of output.

\section{Conclusions}

We offer a simple framework capable of analyzing the economic and political determinants of fiscal budget policies in countries that are part of a Monetary Union. Our framework highlights the important link between

(i) asymmetric information between the Union's decision-making body and member states' governments about each member's potential output - and, therefore, current output gap - and (ii) the issue of potential bail-out among member states in case shocks asymmetrically hit different economies. In an environment characterized by asymmetric information and optimal counter-cyclical fiscal policies, the presence of bailout among member states, first, fosters member states to misreprent their current output gap - e.g., the magnitude of the negative shock hitting their economy - so as to over-borrow on the financial market and, second, lowers lenders' (member states') incentives to discriminate among borrowers' (signal their) types.

Unlike member states, the Monetary Union internalizes the externalites and distortions created by the interplay between bail-out and asymmetric information, and designs a mechanism to discriminate between types of borrowers while preserving (possibly constrained) efficiency. We show that different types of borrowers - characterized by 'high versus low' output gaps - can be separated by means of an appropriate contract linking a maximum level of borrowing on the financial market to an ex-post transfer to be made to the Union. Intuitively, the Monetary Union discriminates 'high-types' (those characterized by a large (negative) output gap) from 'low-types' (those characterized by a small output gap) by imposing on the former an additional ex-post transfer (i.e., interest rate) to be paid when a good state of nature realizes. A downward distortion in the maximum level of borrowing allowed for countries experiencing an economic expansion is introduced when the efficient level of borrowing is high relatively to the member state's ability to repay in the presence of a bad shock, e.g., when, all else equal, the member state's level of outstanding debt is sufficiently high. No distortion is introduced on the level of borrowing of member states experiencing a recession. Finally, governments' shortsightedness may hinder the functioning of the mechanism and, in the extreme, may prevent the Monetary Union from discriminating among borrowers' types.

The latest reforms to the European Monetary Union's fiscal framework have introduced cyclically-adjusted fiscal policies. While such reforms represent an attempt at implementing more efficient counter-cyclical budget deficits, they have generated several controversies between the Union's decision making body and member states' national governments and, as shown in the recent ECB Economic Bulletin (European Central Bank 
[2015]), have performed poorly in many countries. Arguably, such controversies greatly affect the functioning of these rules. To the extent to which controversies hinge on member states' potential output (and output gap), the mechanism proposed in this paper has the advantage of making member states - i.e., the most informed parties - solely responsible for their budget defict choice (subject to constraints), that finally leads to more efficient budget deficits being effectively implemented. 


\section{References}

- Alesina, A., Tabellini, G. (1990). A Positive Theory of Fiscal Deficits and Government Debt. Review of Economic Studies, 57, 403-414.

- Artis, M.J., Buti, M., (200). Close to Balance or in Surplus. A Policy-Maker's Guide to the Implementation of the Stability and Growth Pact. Journal of Common Market Studies 38, 563-592.

- Andres, J., Domènech,R., (2006). Automatic Stabilizers, Fiscal Rules and Macroeconomic Stability. European Economic Review 50, 1487-1506.

- Auerbach, A.J., and Y. Gorodnichenko (2012a), Measuring the Output Responses to Fiscal Policy, American Economic Journal: Economic Policy, 4, 1-27.

- Auerbach, A.J., and Y. Gorodnichenko (2012b), "Fiscal Multipliers in Recession and Expansion" in "Fiscal Policy after the Financial Crisis", A. Alesina and F.Giavazzi (eds), University of Chicago Press.

- Batini, N., Callegari, G. And G.Melina (2012), "Successful Austerity in the United States, Europe and Japan", IMF Working Paper 12/190.

- Baum, A., Poplawski-Ribeiro, M. And A.Weber (2012), "Fiscal Multipliers and the State of the Economy", IMF Working Paper 12/286

- Beetsma, R., Bovenberg, A. (1999). Does Monetary Unification Lead to Excessive Debt Accumulation? Journal of Public Economics 74, 299-325.

- Bordignon, M., Manasse, P., Tabellini, G. (2001). Optimal Regional Redistribution Under Asymmetric Information. American Economic Review 91, 709-723.

- Bottazzi, L., Manasse, P. (2005). Information and Monetary Policy in Common Currency Areas. Journal of Money, Credit and Banking 37, 603-621.

- Brunila, A. (2002). Fiscal Policy: Coordination, Discipline and Stabilization. Helsinki: Bank of Finland.

- Buti, M., Eijffinger, S., Franco, D. (2002). Revisiting the Stability and Growth Pact: Grand Design or Internal Adjustment? EU Commission, Center for Economic Research and Banca d'Italia. 
- Bruck, T., Zwiener, R., (2006). Fiscal Policy Rules for Stabilisation and Growth: A Simulation Analysis of Deficit and Expenditure Targets in a Monetary Union. Journal of Policy Modeling 28, 357-369.

- Cacciotti, M, Caretta,A., De Castro, A. Masi, E., Morea, R. (2014). Metodologie per il calcolo del prodotto potenziale e delle regole del debito e della spesa, previste dal nuovo sistema di governance europea. Italian Ministry of Economy and Finance, Treasury Department, January 28, 2014.

- Canzoneri, M. B., Diba, B.T., (2001). The Stability and Growth Pact: A Delicate Balance or an Albatross? in Brunila, A., Buti, M., Franco, D. (eds) - The Stability and Growth Pact: The Fiscal Architecture of EMU. Basingstoke: Palgrave.

- Christiano, L., Eichenbaum, M, Rebelo, S. (2009), When is the Government Spending Multiplier Large?, Journal of Political Economy 119, 78-121.

- Chari, V.V., Kehoe, P., J., (2007). On the Need for Fiscal Constraints in a Monetary Union. Journal of Monetary Economics 54, 2399-2408.

- Cooper, R., Kempf, H., (2000). "Designing Stabilization Policy in a Monetary Union". NBER Working Paper No.7607.

- Cottarelli, C. (2015). Potential Growth rates and the Working of SGP Fiscal Rules". Vox- CEPR's Policy Portal.

- Cukierman,A., Edwards, S., Tabellini, G. (1992). Seignorage and Political Instability . American Economic Review 82, 537-555.

- Denis, C., Morrow, Mc., Roger, W. (2002). Production Function Approach to Calculating Potential Growth and Output Gaps. Estimates for the EU Member States and the US. Economic Papers 176, European Commission.

- Dixit, A. (2001). Games of Monetary and Fiscal Interactions in the EMU. European Economic Review $45,589-613$.

- Dixit, A., Lambertini, L., (2001). Monetary -Fiscal Policy Interactions and Commitment Versus Discretion in a Monetary Union. European Economic Review 45, 977-987.

- Engwerda, J. C., van Aarle B., Plasmans, J., (2002). Cooperative and non-cooperative Fiscal Stabilization Policies in the EMU. Journal of Economic Dynamics and Control 26, 451-481. 
- European Commission - Directorate General for Economic and Financial Affairs, (2013), "Vade mecum on the Stability and Growth Pact" Occasional Papers 151.

- European Commission (2015), "Commission issues guidance to encourage structural reforms and investment" - Strasbourg, 13 January 2015.

- Ferrero,A., (2009). Fiscal and Monetary Rules for a Currency Union. Journal of International Economics $77,1-10$.

- Galì, J., Monacelli, T., (2005). Optimal Monetary and Fiscal Policy in a Currency Union. Journal of International Economics 76, 116-132.

- Harding, D., and A.Pagan (2002), "Dissecting the Cycle: a Methodological Investigation". Journal of Monetary Economics 49, 365-81.

- Manasse, P. (2007). "Deficit Limits and Fiscal Rules for Dummies". IMF Staff Papers 54, 3.

- Marcellino, M., Musso, A. (2011). The Reliability of Real-Time Estimates of the Euro-Area Output Gap. Economic Modelling 28, 1842-56.

- Roeger, W. (2006). The Production Function Approach to Calculating Potential Growth and Output Gaps. Estimates for the EU Member States and the US.

- Roubini,N., Sachs, J., (1989). Political and Economic Determinants of Budget Deficits in the Industrial Democracies. European Economic Review 33, 903-938.

- Stockman, D.R.,(2001). Balanced-Budget Rules: Welfare Loss and Optimal Policies. Review of Economic Dynamics 4, 438-459.

- Siu, H.E. (2004). Optimal Fiscal and Monetary Policy with Sticky Prices. Journal of Monetary Economics 51, 575-607.

- Tabellini,G., Alesina,.A. (1990). Voting on the Budget Deficit. American Economic Review 80, 37-49.

- Tereanu, E., Tuladhar A., Simone, A. (2014) Structural Balance Targeting and Output Gap Uncertainty. IMF Working Paper, WP/14/107.

- Tirole, Jean (2006), The Theory of Corporate Finance, Princeton University Press. 
- Woodford, M. (2012), "Simple Analytics of the Government Expenditure Multiplier", American Economic Journal: Macroeconomics 3, 1-35.

- Wyplosz, C. (2002). Fiscal Discipline in EMU: Rules or Institutions? Geneva: Graduate Institute for International Studies. 


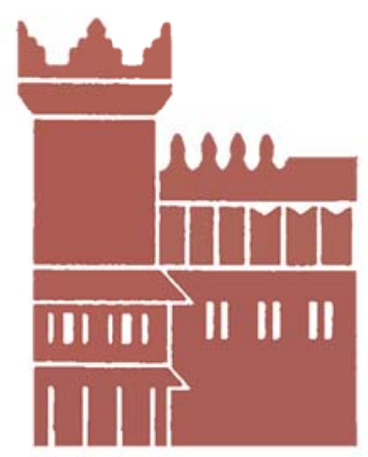

Alma Mater Studiorum - Università di Bologna DEPARTMENT OF ECONOMICS

Strada Maggiore 45

40125 Bologna - Italy

Tel. +39051 2092604

Fax +390512092664

http://www.dse.unibo.it 